\title{
Processamento do sinal acústico em experimento dicótico
}

\section{Acoustic signal processing from a dichotic experiment}

\author{
Leonor Scliar-Cabral* \\ Articulista Convidada
}

\begin{abstract}
RESUMO
Discute-se o processamento do sinal acústico da fala em escuta dicótica de pares mínimos simultâneos, diferindo apenas no primeiro segmento oclusivo, em paroxítonas bissilábicas $\mathrm{CV}$, para verificar o efeito da alfabetização. Metodologia: Participaram 29 crianças com idade média de 7,3 ou 7,4 anos, pertencentes a dois níveis socioeconômicos médio-alto (NSEM) e baixo (NSEB), sendo dez alfabetizadas, pertencentes ao NSEM, oito, ao NSEB e onze não alfabetizadas, somente ao NSEB: as dos grupo alfabetizadas, ao término do $1^{\circ}$ ano do $\mathrm{EF}$ e as do não alfabetizadas, no início. Resultados: embora sem diferenças significativas no número de respostas corretas, intrusões e blendings entre os alfabetizados e não alfabetizados, as respostas se diferenciam quanto às estratégias das duas populações. A alfabetização influencia na maior consistência nas estratégias baseadas na duração, enquanto as dos não alfabetizados são aleatórias, ou difusas. Comprova-se o processamento dos traços fonéticos distintivos que compõem o feixe dos fonemas.
\end{abstract}

Palavras-chave: Experimento dicótico; processamento; sinal acústico da fala; alfabetização; mecanismos atencionais.

DOI: http://doi.org/10.18364/rc.2022n62.522

* Universidade Federal de Santa Catarina, leonorsc20@gmail.com,

Orcid: https://orcid.org/0000-0003-3163-5482

Confluência. Rio de Janeiro: Liceu Literário Português, n. 62, p. 9-40, jan.-jun. 2022 


\section{ABSTRACT}

Speech acoustic signal processing in minimal dichotic listening simultaneous pairs is discussed, differing only in the first occlusive segment, in CV bisyllabic paroxytones, to verify the early literacy effect. Methodology: Twenty-nine children with a mean age of 7.3 or 7.4 years old, belonging to two medium-high (NSEM) and low (NSEB) socioeconomic levels participated: at the Elementary School 1st year end, early literate NSEM ten and NSEB eight children and at the 1st year beginning, only illiterate NSEB eleven. Results: although there were no significant differences in the number of correct answers, intrusions and blendings, between the early literate and illiterate, the answers differ in terms of the two populations strategies. Early literacy influences greater consistency in strategies based on duration, while those of the illiterate are random, or diffuse. The distinctive phonetic features that compose the phoneme bundle processing is confirmed.

Keywords: Dichotic experiment; processing; speech acoustic signal; early literacy; attentional mechanisms.

\section{Introdução}

Discute-se o processamento do sinal acústico obtido através da escuta dicótica de dois pares mínimos simultâneos gravados, que diferiam apenas no primeiro segmento, dos quatro que constituíam o estímulo do vocábulo paroxítono, conforme o padrão ' $\mathrm{CV}+\mathrm{CV}$, sendo o primeiro segmento sempre [+obstruinte], [-contínuo], ou seja, uma oclusiva. Os dados provêm de pesquisa de (SARUBBI, 1988), orientada por Scliar-Cabral, que atuou, durante a orientação, desde a aplicação do instrumento, nas transcrições fonéticas e gráficos até a discussão dos resultados.

Participaram vinte e nove crianças de sete anos, pertencentes a dois níveis socioeconômicos (NSE) diferentes, médio-alto, MA e baixo, B. Dez crianças alfabetizadas do grupo AA, pertencentes ao NSEMA (idade média, 7,3), oito, também alfabetizadas do grupo AB, pertencentes ao NSEB (idade média, 7,4) e onze crianças não alfabetizadas do grupo NA, pertencentes somente ao nível socioeconômico baixo, NSEB (idade média, 7,3) foram 
testadas: as dos grupo $\mathrm{AA}$ e $\mathrm{AB}$, ao término do $1^{\circ}$ ano do Ensino Fundamental (EF) e as do grupo NA, no início do $1^{\circ}$ ano.

Embora no comando, fosse dada a instrução para a criança somente prestar atenção ao que ouvia na orelha assinalada (OA), para repetir o estímulo proveniente daquela orelha, o qual diferia do provindo da orelha contralateral, apenas no primeiro segmento, inúmeras respostas consistiram na fusão (blending) de traços fonéticos extraídos do primeiro segmento dos estímulos provindos de ambas as orelhas.

Esse importante resultado enseja reflexões, por um lado, sobre teorias fonológicas, como a de Jakobson (1967) acerca do fonema, um feixe de traços fonéticos distintivos, por outro, sobre teorias neuropsicológicas acerca dos mecanismos atencionais envolvidos no processamento do sinal acústico da fala. Conforme o modelo de processamento por estágios para reconhecer a palavra falada:

O reconhecimento da palavra falada envolve dois vastos estágios, um perceptual e outro pós-perceptual. Enquanto no primeiro estágio, as operações de segmentação da informação acústica em unidades perceptuais são modulares, no sentido modular de Fodor (1983), no segundo estágio, a saída perceptual é reelaborada por processos atencionais, antes que ocorra o reconhecimento consciente (MORAIS; KOLINSKY, 2002, p. 6, trad. pela autora) ${ }^{1}$.

No segundo item, discutir-se-ão alguns referenciais teóricos provindos da neuropsicologia e da fonética acústica e perceptual que possibilitam atingir o nível explanatório na discussão, enquanto no terceiro, descrever-se-á a

1 Spoken word recognition involves two broad stages, perceptual and post perceptual. Whereas at the first stage, operations of segmentation of the acoustic information into perceptual units are modular in the Fodor's (1983) sense of modularity, at the second stage the perceptual output is re-elaborated by attentional processes before conscious recognition of the word is reached (MORAIS; KOLINSKY, 2002, p. 6).

Confluência. Rio de Janeiro: Liceu Literário Português, n. 62, p. 9-40, jan.-jun. 2022 
metodologia do experimento dicótico. No quarto item, serão apresentados os principais resultados obtidos e, no quinto, as conclusões.

Inspirado nos modelos de máquina da teoria da informação (SHANNON, 1948), Broadbent (1958, p. 5, trad. pela autora) ${ }^{2}$ coloca "ênfase nos problemas de capacidade. A última, na teoria da comunicação, é um termo que representa a quantidade limitada de informação que pode ser transmitida através de um dado canal em um dado tempo".

Para explicar a atenção, Broadbent (1958, p. 39) ainda se vale de metáforas, comparando-a à porta de entrada para a memória. Quando expõe o papel da memória imediata (1958, p. 210), ele está se referindo ao que hoje denominamos Memória de Trabalho, de curtíssima duração, pois o resultado do que é processado permanece somente por milissegundos (ms) e depois se esvai para ceder lugar aos sinais seguintes que demandam processamento.

Broadbent, a partir de evidências obtidas em experimentos com, hoje, denominados dicóticos, divide a atenção em vários estágios, sendo a inicial, aquela em que os neurônios das áreas primárias processam as propriedades físicas, não havendo filtros que inibam o processamento de sinais que serão irrelevantes para o reconhecimento.

Com o desenvolvimento das teorias neuropsicológicas, modelos mais aperfeiçoados sobre os estágios atencionais para fundamentar os experimentos dicóticos têm sido disponibilizados, como os de Morais e Kolinsky (2002). Eles explicam que:

Num experimento dicótico de reconhecimento de palavra (MORAIS et al., 1987), calculamos a proporção de erros com apenas um segmento, por exemplo, a consoante inicial (erros segmentais), e a proporção de erros em, pelo menos, ambos

2 "emphasis on problems of capacity. The latter, in communication theory, is a term representing the limiting quantity of information which can be transmitted through a given channel in a given time" (BROADBENT, 1958, p. 5).

Confluência. Rio de Janeiro: Liceu Literário Português, n. 62, p. 9-40, jan.-jun. 2022 
os segmentos da sílaba (erros globais). (MORAIS et al., 1987; MORAIS, KOLINSKY, 2002, p. 7, trad. pela autora) ${ }^{3}$

O modelo de Morais e Kolinsky não só evidencia um segundo estágio de atenção consciente, como também o efeito da alfabetização sobre o processamento da fala e de direcionamento top down, isto é, da cognição até o periférico.

No Laboratório Haskins, onde se desenvolvem experimentos pioneiros de fonética acústica e perceptual, Liberman e colaboradores (1967, p. 432) partiram da ideia central de que: "As pistas acústicas dos fonemas sucessivos estão de tal forma misturadas entre si na cadeia da fala, que segmentos definíveis de um som não correspondem aos mesmos segmentos no nível do fonema"4. No fluxo das palavras, muitos segmentos acústicos adjacentes interagem na realização de um fonema, acrescendo informações e o mesmo segmento pode trazer informações sobre os adjacentes. Nas oclusivas, alguns de seus índices acústicos são funções do contexto vocálico. Em decorrência, uma mesma consoante pode ser representada por sons fisicamente muito diferentes. Essas consoantes, portanto, são consideradas altamente codificadas. No caso das vogais, esses fonemas manifestam uma menor reestruturação condicionada pelo contexto (op. cit. p. 443).

Mas a conclusão mais relevante dos autores, para a presente discussão, é a de que existe uma modalidade específica para o processamento da fala,

3 In a dichotic word recognition experiment (MORAIS et al., 1987), we calculated the proportion of errors on one segment only, for instance on the initial consonant (segmental errors), and the proportion of errors on at least both segments of a syllable (global errors). The results showed that the proportion of segmental errors was higher in literate than in illiterate people, whereas the proportion of global errors showed the opposite trend. This effect may reflect the availability in literate people, who are aware of phonemes, of an attentional mechanism focusing on the phonemic structure of speech (MORAIS; KOLINSKY, 2002, p. 7).

4 "The acoustic cues for successive phonemes are intermixed in the sound stream to such an extent that definable segments of sound do not correspond to segments at the phoneme level" (Liberman et al., 1967, p. 432).

Confluência. Rio de Janeiro: Liceu Literário Português, n. 62, p. 9-40, jan.-jun. 2022 
caracterizada por processos diferentes daqueles subjacentes à percepção de outros sons (p.443), reforçada por indicações recentes de que os sons da fala e os demais sons são processados primariamente por hemisférios cerebrais diferentes. As evidências provêm, sobretudo, dos experimentos dicóticos, utilizados por Broadbent (1954), ao descobrir que os estímulos apresentados à orelha direita (portanto, sobretudo, ao hemisfério cerebral esquerdo) são mais bem identificados do que os apresentados à orelha esquerda (portanto, sobretudo, ao hemisfério cerebral direito), e o oposto é verdadeiro para melodias e sinais de sonar.

A superioridade da orelha direita, ou, mais precisamente, dos circuitos neurais do hemisfério esquerdo, especializados para o processamento acústico da fala, vem sendo comprovada pelos resultados obtidos com experimentos dicóticos, como é exemplo a pesquisa de Papamanolioudakis (2018), embora a população testada tenha sido pequena, o que exigiu um tratamento estatístico não paramétrico: o reconhecimento dos estímulos recebidos pela orelha direita acusou $\mathrm{m}=11,76 \mathrm{sd}=3,63$ enquanto na esquerda atingiu apenas $\mathrm{m}=6,71 \mathrm{sd}=3,08$.

No entanto, para um melhor entendimento de tais interpretações, é necessário esclarecer, em primeiro lugar, que as conexões neurais podem ser de três tipos (GARMAN, 1990, p. 49-50): contralaterais, quando o axônio se encontra de um lado e os dendritos, no lado oposto; ipsilaterais, quando ambos se encontram no mesmo lado, como, por exemplo, para movimentar os músculos faciais; por último, o que resulta no fenômeno da decussação, metáfora do cruzamento em $\mathrm{X}$, do latim, que significa o cruzamento dos feixes neuronais provenientes de uma área ou região do sistema nervoso provenientes de um lado com os feixes do lado oposto: um exemplo importante desse tipo nos é dado pelo processamento da informação visual, coletada pelos fotorreceptores situados no centro da retina, os cones:

cada vez que um hemisfério aprende uma informação visual nova, este traço de memória é imediatamente transmitido ao outro hemisfério. Tratar-se-ia ali de um mecanismo ativo que visa a manter a coerência dos dois hemisférios. Essa transferência passaria, por certo, pelo corpo caloso, esse vasto feixe de fibras que liga as áreas correspondentes dos

Confluência. Rio de Janeiro: Liceu Literário Português, n. 62, p. 9-40, jan.-jun. 2022 
dois hemisférios. Supondo que esse feixe liga, ponto a ponto, as áreas visuais simétricas dos dois hemisférios, então a transferência entre os hemisférios deveria inverter a direita e a esquerda. É assim que cada uma de nossas lembranças seria simetrizada. (DEHAENE, 2012, p. 292).

Mas o que acontece com o processamento do sinal acústico verbal, proveniente dos experimentos dicóticos? O sinal acústico é transmitido, através de ondas aéreas no ouvido externo e médio, passando por alterações através das vibrações do tímpano e da cadeia ossicular que o preparam para sua codificação em sinais elétricos (potenciais evocados), no ouvido interno, onde se situa a cóclea, um tubo em forma de concha como cobra enroscada, cheio do líquido coclear. A cóclea contém a membrana basilar ondulante, com o órgão de Corti e o nervo coclear que transmite os potenciais evocados para o estágio seguinte, no tronco cerebral e núcleos subcorticais; no órgão de Corti fica também o nervo vestibular, responsável pelo equilíbrio. Nos estágios iniciais, são efetuadas diversas operações, como compensar a debilidade de processamento das frequências mais altas, com o aumento da intensidade, bem como evitar danos, bloqueando, através de filtros, a entrada de sinais muito fortes (GARMAN, 1990, p.52-60).

O estágio seguinte de processamento abrange o tronco cerebral: há conexões ipsilaterais dos ouvidos esquerdo e direito, respectivamente com o lado esquerdo e direito do núcleo coclear, situado na medula, bem na base do tronco cerebral, ao lado da oliva superior. Nas sinapses, o corpo dos neurônios do núcleo coclear se incumbe de tarefas importantes como a de extrair traços críticos na identificação categorial dos sons, como o onset, que, conforme se discutirá, foi essencial para privilegiar as consoantes sonoras em detrimento das homorgânicas surdas, independentemente de qual a orelha assinalada para o sujeito prestar a atenção; o mesmo se pode dizer de outro traço crítico que o corpo dos neurônios do núcleo coclear extrai, o de duração temporal, desta vez, a duração maior do silêncio e do ruído da aspiração nas consoantes oclusivas, no VOT (voice onset time), quando o efeito da alfabetização foi significante; a duração maior do silêncio e do ruído da aspiração nas consoantes oclusivas 
privilegiou a consoante $/ \mathrm{k} /$, em detrimento de $/ \mathrm{p} /$, $/ \mathrm{t} /$, tanto para ensejar um maior número de respostas corretas, quando $/ \mathrm{k} /$ estava no início da palavra estímulo recebida na orelha para a qual o sujeito deveria prestar atenção (OA) e /p/, ou /t/ estava no início da palavra estímulo recebida na orelha para a qual o sujeito não deveria prestar atenção (NA), quanto para ensejar um maior número de intrusões, quando /p/, ou /t/ estava no início da palavra estímulo recebida na orelha para a qual o sujeito deveria prestar atenção $(\mathrm{OA})$ e /k/ estava no início da palavra estímulo recebida na orelha para a qual o sujeito não deveria prestar atenção (NA).

A oliva superior realiza a fusão (blending) da informação auditiva provinda do ouvido direito com a do esquerdo, portanto, há conexões bilaterais, ainda que haja uma pequena diferença de ms. na chegada de tais informações, dependente da maior duração do sinal.

Ainda no tronco cerebral, um importante componente é a formação reticular, uma rede complexa de neurônios que ajustam e integram as informações acústicas recebidas (input), com conexões bilaterais, para o reconhecimento pelas áreas especializadas, no hemisfério esquerdo, da palavra oral. Lado a lado da parte superior da formação reticular se encontra o colículo inferior, responsável por processar input contralateral, refinando características do som relativas à frequência e à amplitude, além de um output motor, portanto, uma interface entre o processamento receptivo e o de produção.

Uma das características importantes desse sistema de processamento auditivo que estamos descrevendo é a de consignar processos top-down, mesmo nos estágios mais iniciais e baixos, isto é, do córtex em direção aos sentidos:

a existência de conexões de duas vias entre o córtex e o tálamo levanta a questão do controle descendente (centrífugo) no sistema auditivo, através do qual centros superiores têm alcance abaixo, para regular processos em níveis inferiores: cerca de 2 por cento das fibras do nervo auditivo carregam informação descendente 
até a cóclea e os músculos da cadeia ossicular. (GARMAN, 1990, p. 63 , trad. da autora) $)^{5}$.

Tal posicionamento refuta teorias como a da modularidade de Fodor, já referida, de que os processamentos mais baixos são exclusivamente encapsulados, compulsórios e verticais.

Chegamos, então, aos estágios mais altos do processamento auditivo da palavra que começam no cérebro, na área primária $41 \mathrm{e}$, depois, na secundária 42 de Brodmann (BRODMANN, GAREY, 2006 [1909], p.122; vide também, a fig. 2).

Para se entender o que é percebido e processado em tais estágios, inclusive nos experimentos dicóticos, são necessários esclarecimentos adicionais.

Em primeiro lugar, o que é detectado inicialmente no sinal, são pistas acústicas (GARMAN, 1990, p. 188), depois codificadas nos traços distintivos de R. Jakobson, já mencionados, como os que distinguem as consoantes sonoras das surdas, por exemplo, no par gola/cola, estímulos do presente experimento (todos os estímulos, tanto na listagem dicótica dissimilar e similar, quanto no teste monaural, iniciavam por consoante oclusiva, vide Anexo A) e não os segmentos [g], [k], em sua integridade: a síntese de tais pistas, então invariantes, nos fonemas $/ \mathrm{g} /, / \mathrm{k} /$ ocorre em etapas subsequentes. Uma das pistas acústicas para distinguir uma consoante oclusiva sonora da surda é a maior duração no VOT, nas primeiras, pista, conforme já comentado, onde o efeito da alfabetização foi significante.

Em segundo lugar, tais pistas acústicas não apresentam limites precisos, separando-as umas das outras, conforme constatado acima por Liberman e

5 "the existence of two-way connections between the cortex and thalamus raises the issue of descending (centrifugal) control in the auditory system, whereby higher centres can 'reach down' to regulate the lower level processes: about 2 per cent of the auditory nerve fibres carry descending information down to the cochlea and the muscles of the ossicular chain. (GARMAN, 1990, p. 63)

Confluência. Rio de Janeiro: Liceu Literário Português, n. 62, p. 9-40, jan.-jun. 2022 
colaboradores (1967, p. 432): o aspecto dinâmico da produção dos sons da fala faz com que haja uma influência recíproca entre pistas adjacentes contínuas e sobrepostas, como se pode observar no sonograma da Figura 1 (SCLIARCABRAL, 2020, p. 125). Observe que as pistas acústicas do VOT da consoante oclusiva surda $[t]$, que comparece três vezes no enunciado "A telha da torre cort(a)", embora se trate da mesma consoante, apresenta uma variação em sua pista mais importante, a duração, dependente de qual a vogal subsequente e de sua posição em sílaba mais intensa versus átona (no primeiro caso, antes da vogal mais intensa ['e], no segundo, antes da vogal mais intensa ['o] e, no terceiro, antes da vogal átona, o chuá [э], cujos primeiro e segundo formantes, que definem as vogais, foram tão fracos, que a autora mal conseguiu percebê-la e nem a registrou na transcrição. Observe, nesse último caso, um exemplo do efeito reciproco de uma das pistas da consoante precedente sobre a vogal seguinte átona, o chuá [๑]: em [ $\lambda \vartheta]$ (última sílaba de "telha"), as pistas da sonoridade de [ $\lambda]$ são bem nítidas, isto é, a ativação da barra da sonoridade bem em baixo, assim como o primeiro e segundo formantes, característicos das pistas vocálicas, o que repercute no chuá [๑], enquanto em [to] (última sílaba de "corta"), tal ativação não ocorre, pois [t] é uma oclusiva surda.

Conforme Garman (1990, p. 19), as pistas assim detectadas são transmitidas para um componente que interpreta e integra tais pistas em classes distintivas de sons, específicas de uma dada língua, os fonemas. Tal componente não se restringe à área 42 de Brodman, no hemisfério esquerdo, pois as redes neurais se projetam para a parte superior de uma área adjacente à 42 , a área 22 de Brodmann, localizada no giro temporal (GTS) do hemisfério esquerdo.

$\mathrm{Na}$ verdade, as pesquisas recentes (FRIEDERICI, 2002, p. 82, 83) que utilizam a imagem por ressonância magnética funcional (fMRI) revelam a existência de redes neurais principais que, no processamento receptivo da linguagem verbal oral, conectam as áreas nela envolvidas no cérebro. A pesquisa de Friederici (2002, p. 79), por se ter ocupado da base neural do processamento auditivo de orações, evidenciou a existência de uma rede neural temporal-frontal bilateral, na qual as áreas temporais do hemisfério esquerdo são responsáveis pelos 
processos que identificam os elementos estruturais, lexicais e fonéticos; o córtex frontal do hemisfério esquerdo está envolvido no sequenciamento e na formação de relações temáticas, semânticas e estruturais enquanto a área da região temporal no hemisfério direito é responsável pela identificação dos parâmetros prosódicos e o córtex frontal do hemisfério direito pelo processamento da melodia da oração.

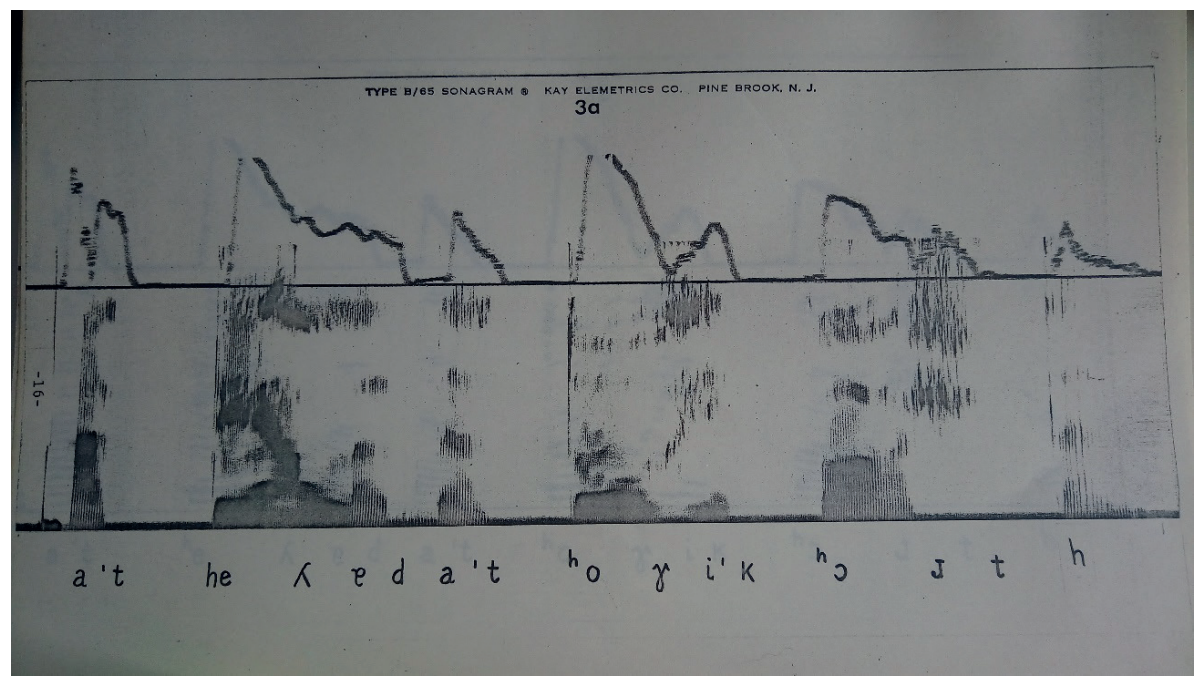

Figura 1. Sonograma de "A telha da torre cort(a)". Fonte: SCLIAR-CABRAL, 2020, p. 125.

Como, nos experimentos dicóticos, os estímulos nunca ultrapassaram o nível de palavras isoladas, os processamentos que envolvem a sintaxe e / ou os parâmetros prosódicos da entoação deixam de ser considerados. Em consequência, as redes neurais em jogo, no seu processamento, são a rede ventral auditiva, responsável por conectar as áreas que reconhecem as pistas acústicas invariantes relevantes e sua síntese em fonemas, a área 42 do HE e a rede dorsal auditiva, responsável pela localização de onde provém o som, bem como pelo comando dos gestos motores da fala, pela alça fonológica na memória de trabalho (áreas 44, 45 e opérculo frontal do HE) e pelo emparelhamento 
com os significantes, do léxico mental fonológico, na memória permanente, no giro temporal superior (GTS) do hemisfério esquerdo.

Em terceiro lugar, é preciso explicar, como, na espécie humana, as respostas comportamentais não serem só contíguas, temporal e espacialmente, aos estímulos acústicos brutos, no paradigma estímulo/resposta, mas também e, primordialmente, o serem mediadas por signos verbais, cujos significantes com base acústica, resultam de processamentos hierarquicamente cada vez mais complexos e psíquicos, conforme se pode inferir do já exposto.

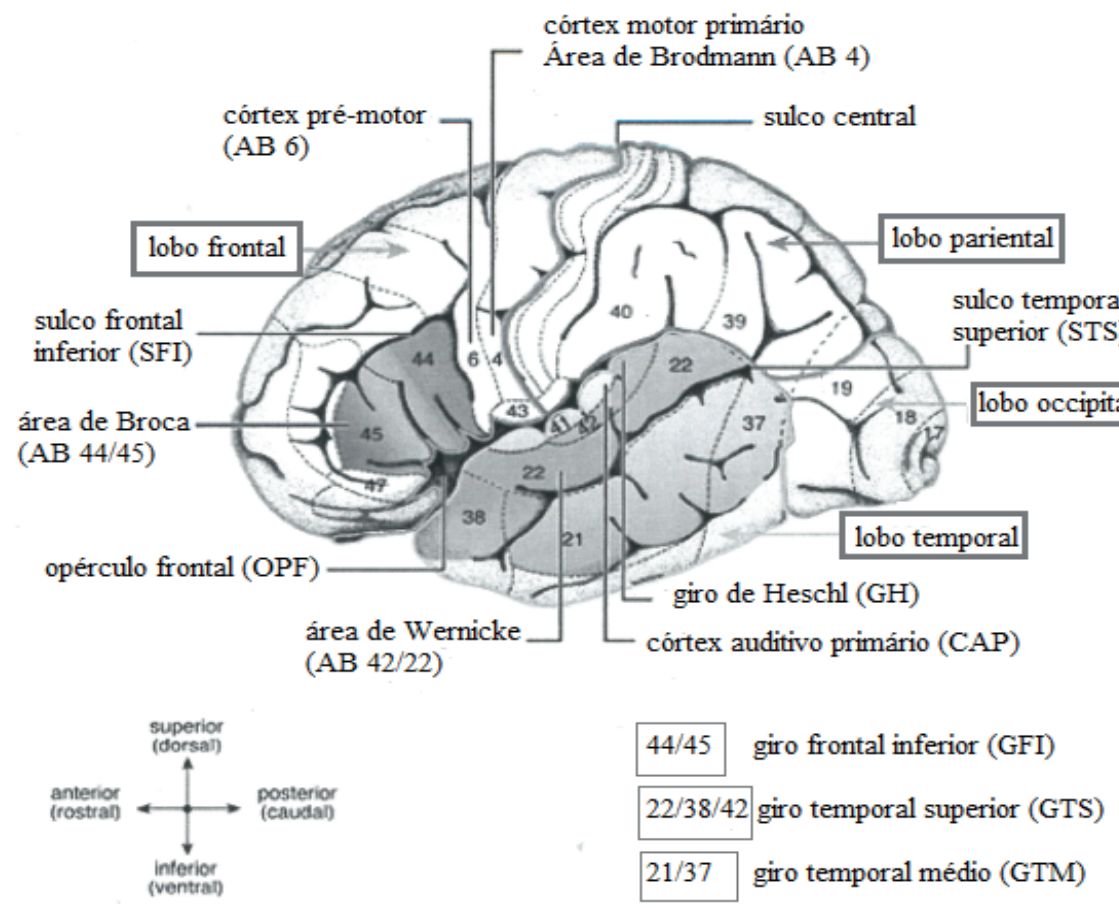

Figura 2. Novas partições do cérebro para as funções da linguagem verbal oral. Vide a área de Broca, localizada no giro frontal inferior (GFI) e a área de Wernicke, localizada no giro temporal superior (GTS), ambas no hemisfério esquerdo.

Fonte: Friederici (2011, adaptado).

Confluência. Rio de Janeiro: Liceu Literário Português, n. 62, p. 9-40, jan.-jun. 2022 
A espécie humana, em virtude do longo período necessário ao neonato para se tornar autônomo, a fim de sobreviver, desenvolveu mecanismos para superar tal deficiência, dentre os quais, viver em sociedade e ser capaz de produzir cultura (D'AQUILI, 1973), sendo o pilar principal, a linguagem verbal oral, através da qual foi possível transmitir conhecimentos a distância, ou à noite, cheia de perigos, sem a necessidade da experiência direta, muitas vezes, arriscada.

Os determinantes biopsicológicos fundamentais foram a estrutura e o funcionamento em níveis hierárquicos, baseados na especialização e divisão de trabalho, garantidas por disposições inatas e pela capacidade de os neurônios humanos aprenderem informações novas, através da experiência.

Assim, uma primeira divisão de trabalho ocorre entre o hemisfério esquerdo (HE) do cérebro, o dominante, na maioria dos indivíduos e o direito (HD): o HE se especializa para os processamentos sequenciais, no tempo, sendo exemplo todas as regras combinatórias das unidades linguísticas e, portanto, da sintaxe, enquanto o HD se especializa para os processamentos holísticos, ou globais, sendo exemplo o reconhecimento dos rostos. Em cada hemisfério há quatro regiões, cada uma delas especializadas para determinadas funções, a temporal, para o processamento das representações mentais dos sinais acústicos, inclusive da fala, esses, no HE, bem como no reconhecimento dos significantes das palavras orais e de seus significados; a parietal, para o processamento das representações mentais das sensações do próprio corpo, dos movimentos dos músculos no espaço (propriocepção e cinestesia) e processos atencionais; a occipital, para o processamento das representações mentais do sinal luminoso (visão) e a frontal, para as respostas e os esquemas motores, o planejamento e a memória de trabalho.

Cada região ainda está subdividida em áreas ou giros em que neurônios se especializam ainda mais, para afinar com e, assim, reconhecer determinados estímulos e não outros, não esquecendo as redes que conectam diferentes áreas ou giros, mesmo em regiões diferentes e até entre os dois hemisférios, de que resultam perceptos de natureza cada vez mais complexa. 
A especialização ocorre, pois, em virtude de fatores inatos, ou seja, de como o cérebro humano está estruturado e funciona, de como amadurece e da experiência. $\mathrm{O}$ amadurecimento decorre de os axônios se estenderem cada vez mais, interligando mais regiões e áreas entre si, mas sobretudo, através da mielinização:

A mielina é uma substância lipoproteica produzida por certos tipos de gliócitos; estas células se enrolam em torno dos axônios, formando uma bainha isolante de mielina que, entre outros, contribui para aumentar a velocidade de propagação do impulso nervoso, atribuindo maior eficiência na transmissão da informação. Dessa forma, o processo de mielinização tem uma relação direta com a aprendizagem. (PINHEIRO, 2007, p.43)

Vejamos o terceiro fator, a experiência: trata-se de um fator externo que, graças à plasticidade dos neurônios humanos para aprender coisas novas, recicla-os, ocasionando mudanças epigenéticas. Ilustraremos esse fator, com o fenômeno do declínio da percepção categorial fonética inata no primeiro ano de vida (SCLIAR-CABRAL, 2004, p. 79-87), uma vez que também servirá para entender por que, nos experimentos dicóticos, as crianças privilegiam determinados traços acústicos invariantes e não a representação aleatória de quaisquer sons:

O recém-nascido demonstra sensibilidade para a percepção categorial, independente da exposição a uma dada língua, conforme os experimentos com o paradigma HAS (high-amplitude sucking), quando ficou comprovada a discriminação categorial da oposição [+]/[-son] no par [ba]/[pa] desde 1 mês de idade (EIMAS et al., 1971, p. 303). Uma linha de pesquisa subsequente procurou rastrear quais categorias são discriminadas e quando se dá o declínio de tais capacidades em favor dos parâmetros da língua que está sendo adquirida. Os resultados evidenciam que os bebês têm uma capacidade linguística geral para discriminar as oposições fonéticas de qualquer língua, as quais declinam gradativamente em favor dos parâmetros da língua que está sendo internalizada. Os indivíduos não percebem oposições que não são pertinentes em sua

Confluência. Rio de Janeiro: Liceu Literário Português, n. 62, p. 9-40, jan.-jun. 2022 
língua nativa, como é o caso dos falantes-ouvintes do espanhol em relação às oposições entre as vogais [-alt, -bx] e [+bx], respectivamente /e/ vs. /E/; /o/ vs. /o/. Os falantes-ouvintes de línguas diferentes ainda diferem quanto a onde estão localizadas as fronteiras na oposição dos segmentos, conforme demonstram Lisker e Abramson (1970, p. 562-567) (SCLIAR-CABRAL, 2004, p. 81).

Antes de passarmos ao item sobre a metodologia do experimento, é importante referir as contribuições de pesquisas recentes com escuta dicótica.

Berretz et al. (2020) evidenciaram que existe uma integração interhemisférica quando os sujeitos tiverem vivenciado situações de estresse antes do experimento dicótico, enquanto Westerhausen e Samuelsen (2020, p. 1) construíram um instrumento cujos traços chave do design do paradigma dicótico foram, como estímulo, um par de sílabas $\mathrm{CV}$, na qual a consoante era sempre uma oclusiva e o comando instruía evocar uma resposta livre, obtendo resultados que confirmaram a confiabilidade de tal instrumento para ser usado tanto em pesquisa quanto para diagnóstico nas clínicas. Já Hugdahl (2016), ao focar o papel da atenção nos experimentos dicóticos, discute o legado de Phil Bryden, pioneiro no uso da neuroimagem funcional em tais experimentos.

\section{Metodologia}

Usou-se o método de escuta dicótica ${ }^{6}$ para testar a hipótese de que a alfabetização tem um efeito reversivo sobre o processamento da cadeia da fala em situação de escuta difícil, aplicado em crianças alfabetizadas e nãoalfabetizadas, com idade de 7 anos.

6 Em um experimento de escuta dicótica, apresentam-se ao sujeito dois estímulos acústicos diferentes simultaneamente às duas orelhas através de fones de ouvido, solicitando-lhe que preste atenção quer a ambos os estímulos, quer, somente, ao que foi apresentado à orelha direita, ou esquerda, visando a, sobretudo, determinar preferência hemisférica para um tipo, ou outro de estímulo.

Confluência. Rio de Janeiro: Liceu Literário Português, n. 62, p. 9-40, jan.-jun. 2022 
O teste consistiu de oito grupos de seis ensaios num total de quarenta e oito pares de palavras similares e quarenta e oito dissimilares (vide ANEXO A). Todas as palavras eram dissílabas paroxítonas, com a estrutura ' $\mathrm{CV}+\mathrm{CV}$, a mais frequente do português e pertenciam ao vocabulário usual. $\mathrm{O}$ experimento foi reaplicado num intervalo de aproximadamente duas semanas, para confirmação do desempenho dos sujeitos.

As expectativas eram:

a) Crianças de sete anos, controladas as variáveis nível socioeconômico e sexo, em duas condições diferentes, alfabetizadas vs. não-alfabetizadas, apresentariam capacidades metalinguísticas de reconhecimento das unidades da fala diversas, em favor do primeiro grupo;

b) A alfabetização causaria como efeito um maior número de acertos nos grupos de alfabetizados (AA) e AB) do que no grupo dos não alfabetizados (NA), comparando-se, porém, especificamente, os grupos AB e NA, para evitar, dentro do possível, a intervenção de outras variáveis, consistindo o efeito maior número de acertos, na maior consistência no tipo de respostas e respostas errôneas menos desviadas do padrão dos estímulos.

\section{Sujeitos}

Crianças alfabetizadas e pré-alfabetizadas de ambos os sexos participaram do experimento. A seleção dos candidatos seguiu os seguintes critérios:

Grupo AA, Alfabetizados, no NSEMA: 1) Estavam alfabetizados (passaram por testes de leitura, antes do experimento); 2) Rendimento familiar médio de 10 salários mínimos; 3) Nível de instrução dos pais: ambos de nível superior, ou, no mínimo, um deles; 4) Cursavam o final do $1^{\circ}$ ano do EF em uma escola particular.

Grupo AB, Alfabetizados, no NSEB: 1) Estavam alfabetizados (passaram por testes de leitura, antes do experimento); 2) Rendimento familiar médio de dois salários mínimos; 3) Nível de Instrução dos pais, primário ou $2^{\circ}$ grau; 4) Cursavam o final do $1^{\circ}$ ano do EF em uma escola pública. Grupo NA, não alfabetizados, no NSEB: 1) Não estavam alfabetizados (passaram por testes de leitura, antes do experimento); 2) Rendimento familiar médio de dois salários mínimos; 3) Nível de instrução dos pais,

Confluência. Rio de Janeiro: Liceu Literário Português, n. 62, p. 9-40, jan.-jun. 2022 
primário ou $2^{\circ}$ grau; 4) Cursavam o início do $1^{\circ}$ ano do EF em uma escola pública.

Obs.: Realizou-se a seleção dos candidatos em fins de 1983, não havendo, portanto, qualquer paridade entre o valor do salário mínimo daquela época e o vigente.

Buscou-se, para garantir um mínimo de 10 Ss para cada grupo, testar mais crianças em cada grupo, na $1^{a}$ sessão, com 11 Ss AA, $10 \mathrm{Ss} \mathrm{AB}$ e $18 \mathrm{Ss}$ NA, esperando-se futuras defasagens. Apesar desses cuidados, a população final ficou assim constituída: o grupo AA constou de 10 crianças, sendo 4 do sexo masculino e 6 do sexo feminino, cursando o final do $1^{\circ}$ ano do EF, cuja média de idade foi de 7 anos e 3 meses. Estudavam em uma escola particular católica, no centro de Florianópolis, seus pais possuíam curso superior e o rendimento mínimo era de 10 salários mínimos. Dos 11 iniciais, 1 deixou de comparecer à $2^{\mathrm{a}}$ gravação.

O grupo AB constou de 8 crianças, sendo 4 do sexo masculino e 4 do feminino, cursando o final do $1^{\circ}$ ano do EF, e sua idade média foi de 7 anos e 4 meses. Estudavam em uma escola estadual, no bairro de Coqueiros, na cidade de Florianópolis; seus pais possuíam instrução primária e o rendimento familiar oscilava ao redor de 2 salários mínimos. Dos 10 iniciais, 2 deixaram de comparecer à $2^{\mathrm{a}}$ gravação.

O grupo NA foi selecionado somente no NSEB, pois, no NSEMA, não se encontravam crianças sem distúrbios cognitivos ou de linguagem, com idade média de 7 anos, não alfabetizadas. O grupo ficou em 11 crianças, sendo 3 do sexo masculino e 8 do feminino. Das 18 crianças iniciais, no grupo masculino, 1 não conseguiu realizar a tarefa e outra recusou-se. Além disso, 4 foram descartadas por não atingirem o teto mínimo no teste monaural e 1 não compareceu à $2^{\mathrm{a}}$ gravação. A média de idade dos sujeitos foi de 7 anos e três meses. Estavam iniciando o $1^{\circ}$ ano do EF. 


\section{Estímulos e Procedimentos}

Os estímulos foram apresentados dicoticamente à proporção de um par a cada cinco segundos, cada ensaio precedido por um bip, como sinal de advertência. As palavras foram pronunciadas por falante paulista e gravadas. Todos os vocábulos iniciavam por uma consoante oclusiva. A seguir, as duas palavras pertencentes ao par a ser utilizado dicoticamente foram gravadas em play back, simultaneamente em dois gravadores sincronizados (Re-vox A77), alimentando os dois canais de um terceiro gravador. A fita final foi posteriormente monitorada por especialista do Laboratório de Psicologia Experimental da Universidade Livre de Bruxelas, num gravador gráfico Oscillomink Siemens, para evitar erros de sincronização que excedessem $10 \mathrm{~ms}$. Neste artigo, comenta-se em profundidade apenas o teste similar cujos pares diferem somente no segmento inicial.

\section{Procedimentos}

Os estímulos foram apresentados aos sujeitos aproximadamente a 70 dB SPL através de um 4-Band Estéreo Rádio Cassete Recorder-Rg-700, marca Polyvox, ao qual foram acoplados os fones estéreos de ouvido. Os sujeitos foram testados individualmente em sala isolada, na própria escola. Foi testada a audição de cada sujeito, através de teste monaural de palavras. Testou-se, também, se esses sujeitos seriam destros ou sinistros, de mãos, pés e olhos, antes do início do experimento.

No experimento dicótico, procurava-se deixar as crianças bem à vontade. Em seguida, era-Ihes explicado que, através dos fones de ouvido, ouviriam palavras simultaneamente, como se duas pessoas estivessem falando do lado direito e do esquerdo. A tarefa consistiria em prestar atenção à orelha indicada pelo experimentador e repetir o que ouvisse, mesmo em dúvida quanto à clareza das palavras. A cada seis ensaios, a orelha a que deveria prestar atenção era mudada assim como os fones de ouvido.

O repetido pelos sujeitos foi gravado simultaneamente em um MicroCassete Recorder Polyvox MC3500, ao mesmo tempo em que uma das 
participantes efetuava a transcrição fonética. $\mathrm{O}$ experimento foi reaplicado num intervalo de duas semanas, procedendo-se exatamente igual ao do primeiro e com os mesmos sujeitos, iniciando-se a atenção seletiva pela outra orelha. Para garantir o resultado do tratamento dos dados, as fitas foram posteriormente ouvidas e revisada a transcrição fonética das duas sessões.

Fizeram parte do experimento três pessoas: uma que ajudava a assinalar a orelha, outra que cuidava do equipamento e uma terceira que transcrevia foneticamente in loco.

\section{Discussão dos resultados}

Para verificar se havia variação entre uma orelha e outra e entre uma gravação e outra, foi utilizado o Teste T para grupos correlacionados a nível de significância 0.05 .

Para verificar nos dois experimentos o efeito da alfabetização, foi usado o teste T, para grupos independentes, variância homogênea, a nível de significância 0.05 .

Eis a classificação de respostas possíveis, cujos exemplos podem ser mais bem visualizados na Tabela 1:

\begin{tabular}{|c|c|c|c|c|c|c|c|}
\hline & PAR & $O A$ & ONA & RESPOSTA & GRUPO & GRAVAÇÃO $S$ & SUJEITO \\
\hline$c=$ correta & 47 & 'dadu & 'gadu & 'dadu & $A A$ & 19 & s6 \\
\hline$I=$ intrusão & 36 & 'kalu & 'galu & 'galu & $\mathrm{AA}$ & 19 & s3 \\
\hline $\mathrm{B} 1=$ blendings & 25 & 'tolu & 'bolu & $\begin{array}{l}\text { 'dolu } \\
\text { 'polu }\end{array}$ & $\mathrm{AA}$ & $1 a ̣$ & s7 \\
\hline $\mathrm{Al}=\underset{(1 \text { segmento })}{\operatorname{ano}}$ & 7 & 'kozu & 'gozu & $\begin{array}{l}\text { 'bozu } \\
\text { 'tozu } \\
\text { 'koku }\end{array}$ & $\mathrm{NA}$ & 19 & s4 \\
\hline $\mathrm{A} 2=\underset{(2 \text { segmentos })}{\text { anômalas }}$ & 2 & 'koku & 'poku (poku) & $\begin{array}{l}\text { 'kõgu - } \\
\text { 'totu }\end{array}$ & $\begin{array}{l}\text { NA } \\
\text { NA }\end{array}$ & $\begin{array}{l}19 a \\
2 a\end{array}$ & $\begin{array}{l}\text { s13 } \\
\text { s7 }\end{array}$ \\
\hline $\begin{array}{l}G=\text { erros globais } \\
N=\text { nulo } \\
G=\text { erros globais } \ldots M=\text { err }\end{array}$ & $\begin{array}{c}9 \\
5 \text { maciços }\end{array}$ & 'gatu & 'patu & $\begin{array}{l}\text { to } \\
\varnothing\end{array}$ & NA & 1 ạ & $\mathrm{s} 12$ \\
\hline
\end{tabular}

Confluência. Rio de Janeiro: Liceu Literário Português, n. 62, p. 9-40, jan.-jun. 2022 
$C-$ Correta $O D \quad O E$

Considera-se resposta correta, dado o par 'dadu - 'gadu, simultaneamente, tendo sido 'dadu o estímulo na orelha assinalada (OA), se a resposta for 'dadu.

\section{$I$ - Intrusão $O D \quad O E$}

Dado o par 'kalu - 'galu, simultaneamente, tendo sido 'kalu o estímulo na orelha assinalada, se a resposta for 'galu, houve intrusão.

\section{BI - Fusão fonética (Blending)}

Considera-se fusão fonética (blending) a extração de um traço do estímulo de uma orelha, por exemplo, [+ ou - sonoridade], combinando-o com o traço extraído da outra orelha, por exemplo, zona de articulação. Dadas as palavras 'tolu-'bolu, à $\mathrm{OD}$ e à $\mathrm{OE}$ simultaneamente, o sujeito deveria responder 'tolu se a OD fosse a assinalada, ou 'bolu, se fosse a OE, mas produziu 'dolu, compondo o fonema inicial, que contém todavia a zona de articulação do fonema /t/ da palavra 'tolu e [+sonoridade] do fonema /b/ da palavra 'bolu. Poderia, ainda, produzir o blending 'polu, pelo mesmo raciocínio.

\section{Al - Anômalas (1 segmento)}

Considera-se resposta anômala 1, a troca de um fonema na resposta solicitada, sem incorrer em intrusão, ou blending. Dado o par 'kozu - 'gozu, se a resposta for bozu, houve, portanto, alteração de um segmento, originando outra palavra que não a solicitada.

\section{A2 - Anômala (2 segmentos)}

Considera-se resposta anômala 2, a troca de dois fonemas na resposta solicitada. Dado o par 'koku - 'poku, se a resposta dada for 'totu, houve alteração de 2 (dois) segmentos. 


\section{G - Erro Global ou Maciço}

Caracteriza-se o erro global, ou maciço pela resposta na qual ocorrem violações de três segmentos e/ou houve modificações na estrutura vocabular (vide Tabela 2).

\section{Tabela 2. Resultado Estatístico dos Erros nos Grupos AB vs NA

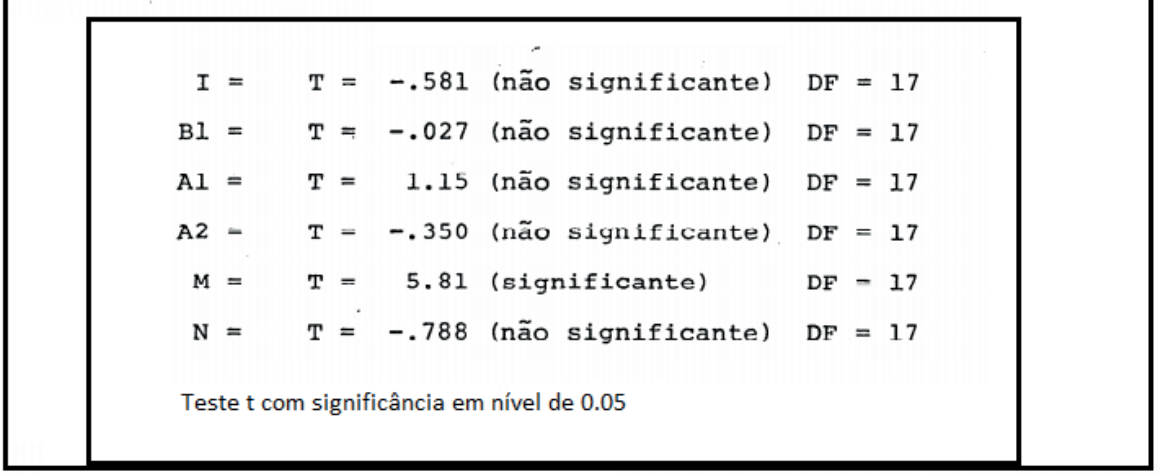

Fonte: Adaptado de Sarubbi (1988, p. 41).

Dado o par 'gatu-'patu, o sujeito responde 'to.

$\mathrm{N}$ - Nada, quando o sujeito não emite nenhuma resposta.

Comparando-se as porcentagens dosresultadose aplicando-se otratamento estatístico teste - $T$, não houve diferenças significantes entre as populações no que concerne ao tipo de erro relativo, a não ser num único caso: verificou-se que entre os alfabetizados e os não alfabetizados, nas respostas maciças, houve diferença significante ao nível de 15.81 ( $\mathrm{DF}=17$, nível de significância, 0.05 , vide Tabela 2). Os erros maciços serão comentados adiante qualitativamente.

Os resultados mostram que a extração dos traços fonéticos nos experimentos dicóticos não é afetada pela alfabetização até o $l^{\circ}$ ano concluso, nem tampouco há diferenças determinadas pelo NSE, conjeturando-se que outras capacidades, que não as automáticas, sejam as mais afetadas por esses dois fatores. 
A questão mais instigante nos resultados é: Por que não houve uma diferença significante em favor do processamento no hemisfério esquerdo, isto é, dos estímulos apresentados à orelha direita, já que, desde os trabalhos pioneiros de Kimura (1961) com escuta dicótica, era esperada a vantagem quando o input proviesse do ouvido direito?

Em primeiro lugar, deve ficar bem claro que, quando se designa orelha, ou ouvido direito, no contexto dos experimentos dicóticos, não se está referindo a onde, efetivamente, ocorre o reconhecimento da palavra oral, possibilitado pelos feixes neurais em áreas especializadas do hemisfério esquerdo. Não existe superioridade do ouvido externo, médio ou interno direito sobre o esquerdo para suas operações mecânicas ou elétricas sobre as ondas acústicas da fala.

Uma explicação de por que as respostas dadas pelos sujeitos, discutidas no presente estudo, não revelam uma diferença estatisticamente significante de preferência do hemisfério esquerdo para o processamento, encontra-se no trecho já referido de Morais e Kolinsky (2002, p. 6): provavelmente, o reconhecimento da palavra estímulo ateve-se ao primeiro estágio, o perceptual, de forma modular (FODOR,1983), o que significa, de forma compulsória, automática (não consciente) e bottom up (dos sentidos em direção à percepção). $\mathrm{O}$ fato de o processamento ser compulsório e não consciente (dispensando os mecanismos atencionais) não bloqueou o processamento do estímulo colhido pelo outro ouvido, o que foi corroborado pelo grande número de intrusões e de blendings em ambos os grupos de alfabetizados e de não alfabetizados.

\section{Padrões}

Constata-se um contraste muito grande entre o número de acertos e erros, dependente do tipo de estímulo, exigindo investigação, embora já esperado, se o estímulo contiver uma consoante [-son] na OA vs uma [+son] na ONA, ocorrendo um número muito grande de intrusões. Isto realmente aconteceu, mas não explicava a reação das três populações a outros tipos de estímulo, dada de forma consistente principalmente para os alfabetizados. A conclusão foi a de que os seguintes padrões atuavam de forma consistente: 


\section{I - Previsão de maior número de respostas corretas}

Orelha assinalada (OA) [+son] Orelha não assinalada (ONA) [- son]

Dado o padrão acima (pares 1, 3, 10, 18, 19, 23, 28, 30, 31,37, 38, 40 e 43), quando um estímulo sonoro ocorre em contraposição a um estímulo surdo, houve prevalência do estímulo sonoro conforme previsto, em razão da maior duração dos sinais (VOT) implicados na sonoridade no português. Para um total de 812 estímulos, houve 480 acertos.

\section{II - Previsão de maior número de erros}

OA [-son] ONA [+sn]

Dado o padrão acima (pares 4, 6, 7, 12, 13, 17, 21, 24, 25,29, 32, 35, $36,42,45,46$ e 48) quando um estímulo surdo ocorre em contraposição a um sonoro, pode-se verificar que o índice de acertos foi insignificante, em contraposição ao grande número de intrusões, ocasionadas pela sonora na orelha contralateral. Para 1.044 estímulos, houve 133 acertos.

\section{OA $/ k / \quad$ ONA $/ p /$ ou $/ t /$}

Ao contrário da expectativa, os pares 2, 5, 11, 16 e 34 ocasionaram o maior número de acertos, provando que, de algum modo, os sujeitos se apoiaram numa pista fornecida pela consoante oclusiva velar surda, em contraposição à alveolar e labial surdas, ou seja, no ruido mais forte e com duração maior no onset, fenômeno ainda não suficientemente investigado no português. Para um total de 290 estímulos, houve 213 acertos.

\section{OA $/ p /$ ou $/ t / \quad$ ONA / $/$}

Este padrão (itens 08,22 e 41) confirma a preferência da velar surda em contraposição às labiais e alveolares, dado o grande número de intrusões. Dentro desse padrão, para 232 estímulos houve somente 93 acertos. 


\section{$O A[+s n] \quad O N A[+s n]$}

Trata-se de um contexto altamente competitivo, ocasionando muitos erros. Nesse padrão, temos os pares 20,27, 44 e 47. Conclui-se que, numa situação competitiva, havendo oclusiva velar na contralateral, há maior possibilidade de intrusões, diminuindo as probabilidades de outros tipos de resposta, confirmando as vantagens de processamento das velares. Para um total de 232 estímulos, houve 66 acertos, no padrão OA [+sn], ONA [+sn].

\section{Contexto nasal}

Como dos três pares em que ocorreu /p/, em dois, ele ocorreu em contexto nasal, não se atribui a incidência de erros apenas ao /p/ na OA, em contraste com as outras oclusivas surdas na ONA, pois o efeito da ressonância nasal determinou que tais itens apresentassem um grande número de erros.

\section{Anômalas}

Foram considerados dois tipos de respostas anômalas, sempre conservando a estrutura ' $\mathrm{CV}+\mathrm{CV}$ : anômalas com erro de um segmento e com erros de 2 segmentos. Para o grupo NA que realizou um porcentual médio de erros relativos de 11,73\% (85) de anômalas do tipo 1 e de 9,68 (70) de anômalas do tipo 2 , houve um total de 65 palavras não existentes na língua portuguesa.

No grupo $A B$, que realizou um porcentual médio de erros relativos de 7,27\% (33) anômalas 1 e de 10,68 (50) de anômalas 2, houve 42 ocorrências de palavras não existentes na língua, enquanto no grupo AA, para um porcentual médio de erros relativos nas anômalas 1, ocorreram $65 \%$ (37) e 12,70\% nas (83) anômalas 2; houve, contudo, 51 ocorrências de palavras não existentes no português.

Nada assegura, no entanto, que algumas das palavras produzidas pelas crianças não sejam de seu léxico infantil e/ou sociolinguístico. O grande número de palavras não existentes no léxico conduz à hipótese de que na 
situação experimental de escuta difícil, as crianças processem o sinal acústico da fala sem emparelhamento com o léxico internalizado, confirmando a explicação de Morais e Kolinsky $(2002$, p. 6) de os sujeitos se aterem ao primeiro estágio perceptual de reconhecimento da palavra.

\section{Erros Globais ou Maciços}

Comentando os erros maciços, convém assinalar que a única diferença significante encontrada nos resultados foi o percentual médio dos erros maciços relativos ao total de erros nos grupos NA e AB, confirmando os achados de Morais et al. (1987). O grupo NA não somente comete maior número de erros maciços, mas também comete violações maiores e em maior número quanto à estrutura vocabular. Dos três grupos, $\mathrm{AA}, \mathrm{AB}$ e NA, o único a não cometer violações do padrão é o grupo AB. O grupo NA apresentou 10 respostas com a estrutura $\mathrm{CV}$, preservando, às vezes, alguns traços da silaba de intensidade (ex. ['potfi - 'dotfi], resposta ['bí] (S4, item 24); às vezes, preservando a silaba que era átona, agora produzida isoladamente (ex. ['bale] ['pale], resposta [la] (efeito da recência de a sílaba átona ser o último estímulo a ser processado), (S12, item 18). Outras vezes, nenhum traço persistiu, como em ['lu], com exceção da lateral, (S13, item 38). O grupo AA apresentou duas emissões com a estrutura $\mathrm{CV}$ : numa delas captou o traço sonoro do estimulo contralateral ['kozu - 'gozu], resposta ['go] (intrusão), (Sujeito 11, item 7). O mesmo sujeito emitiu uma resposta $\mathrm{CV}$, totalmente discrepante do estímulo, no item 36 ['kalu - 'galu], resposta [' dã]. No grupo NA, houve também respostas com acréscimo de sílaba: Ex. [bo’dures], para os estímulos ['bodes - 'todes].

\section{Fusão Fonética (Blending)}

Para que ocorra a fusão fonética (blending), dois traços precisam estar em jogo no par: [+, -son], mais o traço diferente no ponto de articulação. Havia os seguintes pares que ensejavam o blending: 1, 4, 9, 10, 13, 11, 19, 21, 
$24,25,29,31,35,37,43$ e 46 . De acordo com os traços que estavam em jogo, ocorreram as seguintes respostas:

$\begin{array}{llll}\text { Item } & \text { OA } & \text { ONA } & \text { RESPOSTA } \\ 17 & \text { 'pule } & \text { 'gule } & \text { Rsn - 'bule } \\ 43 & \text { 'dãnu } & \text { 'pãnu } & \text { Rsn - 'bãnu } \\ 4 & \text { 'pẽfi } & \text { 'dẽtfi } & \text { Rsd - 'teli }\end{array}$

Verifica-se que os grupos AA e AB tiveram muita consistência nas respostas, favorecendo a resposta sonora. Quanto ao grupo NA, produziu o menor número de blendings porcentualmente e não foi consistente como os grupos $\mathrm{AA}$ e $\mathrm{AB}$, que se apoiaram quase que exclusivamente na sonoridade.

Os resultados do blending vêm corrobar que, embora não haja diferenças significantes entre os grupos quanto ao tipo de respostas, com exceção dos erros maciços, um exame mais acurado revela que os grupos alfabetizados desenvolvem estratégias mais consistentes, apoiando-se no traço [+ son].

Mas, no plano teórico, o blending confirma, empiricamente, a definição de Jakobson (1967) acerca do fonema como um feixe de traços fonéticos distintivos, pois o que está sendo fundido são os traços fonéticos extraídos dos fonemas nas duas palavras.

\section{Considerações finais}

Os resultados deste experimento demonstram que, embora não haja diferenças significativas no número de respostas corretas, no número de intrusões e no número de blendings entre a população de alfabetizados e não alfabetizados, a natureza das respostas se diferencia quanto às estratégias utilizadas pelas duas populações.

A influência da alfabetização demonstra uma maior consistência nas estratégias baseadas na duração, se comparadas àquelas utilizadas pela 
população de não alfabetizados que se mostram mais aleatórias ou difusas. Esta conclusão se apoia no fato de que o maior número de respostas corretas, na população, acompanha de forma mais consistente o padrão:

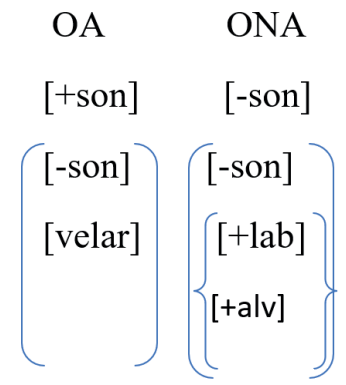

As respostas incorretas seguem o reverso dos estímulos acima. Nas intrusões, o padrão de respostas desta mesma população é o seguinte: [-son] na OA e [+ son] na ONA, enquanto os não alfabetizados incorrem em muitas intrusões quando na ONA há [-son]. Nas fusões fonéticas (blendings), a população alfabetizada raramente dá respostas utilizando o traço [-son]. Tais respostas também demonstram o efeito do tipo de padrão dos estímulos.

Verificou-se que, entre os alfabetizados e os não alfabetizados, nas respostas maciças, houve diferença significante ao nível de 15.81 ( $\mathrm{DF}=17$, nível de significância, 0.05).

O grande número de respostas de palavras não existentes no léxico, embora obedecendo à estrutura vocabular do estímulo ( $\left.{ }^{\circ} \mathrm{CV}+\mathrm{CV}\right)$, fortalece a hipótese de que neste experimento é suficiente aos sujeitos passar pelo estágio de transdução do sinal acústico e tratamento fonético, do reconhecimento da estrutura vocabular, incluindo o traço suprassegmental da intensidade, da análise e síntese dos traços fonéticos e aplicação das regras fonotáticas da língua, sem contudo, emparelhar com morfemas e/ou com o léxico internalizado, atendo-se ao processamento bottom-up. Resta a possibilidade de investigar se os sujeitos aprenderam a forma canônica do estímulo, que 
era sempre a mesma, ou se as respostas ' $\mathrm{CV} \mathrm{V}_{+} \mathrm{CV}$ resultam do reconhecimento de pistas acústicas para a identificação deste padrão, porque os resultados de Sarubbi (1988, p. 75) indicam que, embora não seja significante a diferença entre a $1^{\mathrm{a}}$ e a $2^{\mathrm{a}}$ gravações, ela favorece levemente a $2^{\mathrm{a}}$ (nível de significância $\mathrm{T}=-4.08719$ ).

Mas o mais instigante, para a presente discussão, é: Por que não houve uma diferença significante em favor do processamento no hemisfério esquerdo, isto é, dos estímulos apresentados à orelha direita, já que, desde os trabalhos pioneiros de Kimura (1961) com escuta dicótica, era esperada a vantagem quando o input proviesse do ouvido direito?

Por que os resultados não confirmam que existe uma preferência pelo hemisfério esquerdo, caracterizada por processos diferentes daqueles subjacentes à percepção de outros sons (BROADBENT, 1958), reforçada por indicações recentes de que os sons da fala e os demais sons são processados primariamente por hemisférios cerebrais diferentes? Segundo o mesmo autor, as evidências proviriam, sobretudo, dos experimentos dicóticos, ao descobrirem que os estímulos apresentados à orelha direita (portanto, processados, sobretudo, no hemisfério cerebral esquerdo) são mais bem identificados do que os apresentados à orelha esquerda (portanto, processados, sobretudo, no hemisfério cerebral direito).

Uma explicação de por que as respostas dadas pelos sujeitos, discutidas no presente estudo, não revelam uma diferença estatisticamente significante de preferência do hemisfério esquerdo para o processamento, encontra-se no trecho já referido de Morais e Kolinsky (2002, p. 6): provavelmente, o reconhecimento da palavra estímulo ateve-se ao primeiro estágio, o perceptual, o que significa, de forma compulsória, automática (não consciente) e bottom up (dos sentidos em direção à percepção). $\mathrm{O}$ fato de o processamento ser compulsório e não consciente (dispensando os mecanismos atencionais) não bloqueou o processamento do estímulo colhido pelo outro ouvido, o que foi corroborado pelo grande número de intrusões e de blendings em ambos os grupos de alfabetizados e de não alfabetizados. 


\section{Agradecimentos:}

Agradeço à Ivone Moraes Sarubbi (1988), minha orientanda, a utilização de muitos dados que colhemos juntas e os analisamos, durante a pesquisa de mestrado, pioneira, no Brasil.

\section{Referências}

BERRETZ, G.; PACKHEISER, J.; WOLF, O. T.; OCKLENBURG, S. Dichotic listening performance and interhemispheric integration after stress exposure, Scientific Reports. Scandinavian Journal of Psychology, Oslo, v. 10, n.1, 2020. DOI: $10.1038 /$ s41598-020-77708-5.

BROADBENT, D. E. The role of auditory localization in attention and memory span. Journal of Experimental Psychology, Washington, DC, p. 191-196, 1954.

BROADBENT, D. E. Perception and communication. Long Island, NY: Pergamon, 1958, $338 \mathrm{p}$.

BRODMANN, K.; GAREY, L. J. Brodmann's Localisation in the Cerebral Cortex - The Principles of Comparative Localization in the Cerebral Cortex Based on Cytoarchitectonics. Translated from German with editorial notes and an introduction by Garey, L. J. 3. ed. New York: Springer Science + Business Media, Inc., 2006 [1909].

D'AQUILI, E. G. The biopsychological determinants of culture. An AddisonWesley Module in Anthropology. Reading, Mass.: Addison-Wesley, 13, 1973.

DEHAENE, S. Os neurônios da Leitura - como a Ciência explica a nossa capacidade de ler. Consultoria, tradução e supervisão de Scliar-Cabral, L. 1. Ed. Porto Alegre: Penso, 2012, 374 p.

EIMAS, P. D.; SIQUELAND, E. R.; JUSCZYK, P.W; VIGORITO, J. Speech perception in infants. Science, Washington, DC, v. 171, n. 3968, p. 303-306, Jan. 22, 1971. 
FODOR, J. A. The modularity of mind. Cambridge, MA: MIT Press, 1983, $153 \mathrm{p}$.

FRIEDERICI, A. D. Towards a neural basis of auditory sentence processing. Trends in Cognitive Sciences, Amsterdam, v. 6, n. 2, p. 78-84, fev. 2002.

FRIEDERICI, A. D. The current Model. Physiological Reviews, v. 91, n. 4, p. 1357-1392, 2011. Disponível em: <http://www.cbs.mpg.de/mitarbeiter/ friederici/current-model $>$. Acesso em 04 ag., 2016.

GARMAN, M. Psycholinguistics. Cambridge, UK: Cambridge University Press, 1990, p. 512.

HUGDAHL, K. Dichotic listening and attention: the legacy of Phil Bryden. Laterality, Londres, v. 21, n. 4-6, p. 433-454, 2016 Jul-Nov.

JAKOBSON, R. Fonema e fonologia. Trad. de J. Mattoso Camara Jr. Rio de Janeiro: Acadêmica, 1967, 187 p.

KIMURA, D. Some effects of temporal-lobe damage on auditory perception. Canadian. J. Psychol., Waterloo, ON, Canada, v.15, p. 156-65, 1961.

LIBERMAN, A. M.; COOPER, F. S.; SHANKWEILER, D. P.; STUDDERTKENNEDY, M. Perception of the speech code. Psycholoqy Review, Washington, DC, v. 74, n. 6, p. 431-461, nov.1967.

LISKER, L.; ABRAMSON, A. S. The voicing dimension: some experiments in comparative phonetics. Proceedings of the Sixth International Congress of Phonetic Sciences. Praga: Academia Publishing House of the Czechoslovak Academy of Sciences, 1970, p. 562-567.

MORAIS, J.; CASTRO, S. L.; SCLIAR-CABRAL, L.; KOLINSKY, R.; CONTENT, A. The Effects of Literacy on the Recognition of Dichotic Words. Quarterly Journal of Experimental Psychology, Section A, v. 39, n. 3, p. 451-465, ag. 1987. https://doi.org/10.1080/14640748708401798 
MORAIS, J.; KOLINSKY, R. Literacy effects on language and cognition. In: BÄCKMAN, L.; HOFSTEN, C. von (Orgs.). Psychology at the turn of the millennium. Cognitive, biological, and health perspectives. Londres: Psychology Press/Taylor \& Francis (Reino Unido), 2002, v. 1, p. 507-530. Disponível em: <https://www.research gate.net/publication/285765555 Literacy_effects_on_language_and_cognition>. Acesso em 29 mar. 2021. PAPAMANOLIOUDAKIS, G. Dichotic Listening Experiment. UK Essays, Nottinghamshire, UK, nov. 2018. Disponível em $<$ https www.ukessays.com/?url= https $\% 3 \mathrm{~A} \% 2 \mathrm{~F} \% 2 \mathrm{Fwww}$. ukessays. com $\% 2 \mathrm{Fessays} \% 2 \mathrm{Fpsychology} \% 2 \mathrm{Fdichotic}-1$ istening-experiment-5453. php\%23citethis>. Acesso em 08 jun., 2021.

PINHEIRO, M. Fundamentos de neuropsicologia - O desenvolvimento cerebral da criança. Vita et Sanitas, Trindade/Go, v. 1, n.1, p. 34-48, 2007

SARUBBI, I. M. Experimentos dicóticos em crianças alfabetizadas e préalfabetizadas. 1988. 82 f. Dissertação de Mestrado. Programa de PósGraduação em Linguística. Universidade Federal de Santa Catarina, 1988.

SCLIAR-CABRAL, L. Declínio da percepção categorial fonética inata no primeiro ano de vida. Letras de Hoje, v. 39, n. 3, p. 79-87, 2004.

SCLIAR-CABRAL, L. Sonogramas de enunciados português brasileiro. In: ALMEIDA CASTRO, L. H.; VIANA de CARVALHO MORETO, F.; TEIXEIRA PEREIRA, T. (Orgs.). Problemas e Oportunidades da Saúde Brasileira. Ponta Grossa: Atena Editora, v. 7, p. 118-127, 2020.

SHANNON, C. E. A mathematical theory of communication. Bell System Technological Journal, New Jersey, n. 27, p. 379- 423, 1948.

WESTERHAUSEN, R.; SAMUELSEN, F. An optimal dichotic-listening paradigm for the assessment of hemispheric dominance for speech processing, Plos One, São Francisco, v. 15, n. 6, (e0234665), (2020). 


\section{ANEXOS}

ANEXO A

IISTAGEM DICOTICA

DISSIMILAR

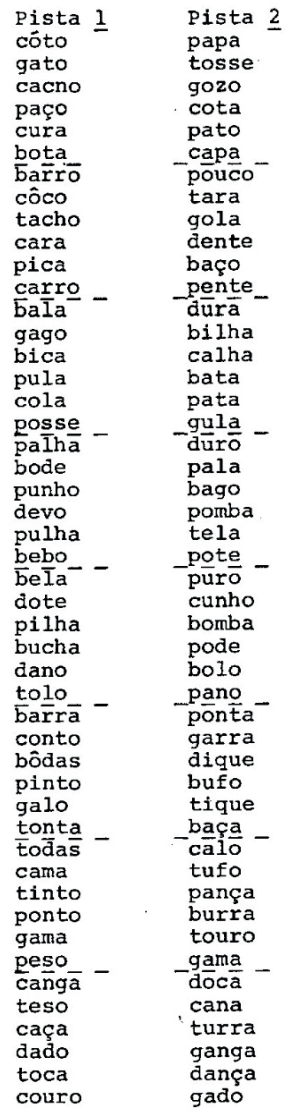

MONOAURAL

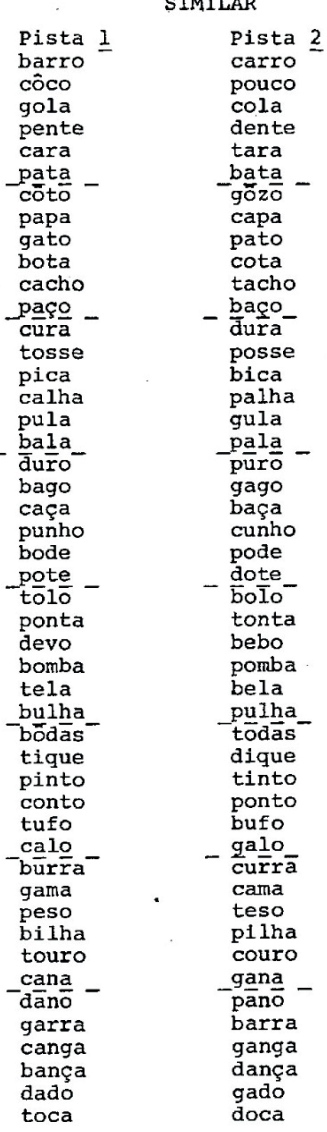

cura
dura
tosse
posse
pica
bica
bodas
todas
tique
dique
pinto
tinto_

